\title{
As teias que a Síndrome de Down não tece: identidade, estigma e exclusão social
}

How Down Syndrome Does Not Weave Webs: Identity, Stigma and Social

Exclusion

Les réseaux faibles du syndrome de Down: identité, stigmatisation et exclusion sociale

Marina Dias de Faria

\section{OpenEdition}

\section{Journals}

Edição electrónica

URL: http://journals.openedition.org/rccs/10707

DOI: $10.4000 /$ rccs. 10707

ISSN: 2182-7435

\section{Editora}

Centro de Estudos Sociais da Universidade de Coimbra

Edição impressa

Data de publição: 1 setembro 2020

Paginação: 119-144

ISSN: 0254-1106

\section{Refêrencia eletrónica}

Marina Dias de Faria, «As teias que a Síndrome de Down não tece: identidade, estigma e exclusão social », Revista Crítica de Ciências Sociais [Online], 122 | 2020, posto online no dia 10 setembro 2020, consultado o 15 setembro 2020. URL : http://journals.openedition.org/rccs/10707 ; DOI : https:// doi.org/10.4000/rccs. 10707 


\title{
MARINA DIAS DE FARIA
}

\section{As teias que a Síndrome de Down não tece: identidade, estigma e exclusão social}

\begin{abstract}
A presente pesquisa teve como objetivo utilizar a teoria das redes para analisar a configuração das teias sociais de adultos com Síndrome de Down (SD). Esta teoria tem como principal contribuição apontar que o indivíduo é condicionado pelo tecido social que o envolve, sendo também capaz de modificar este tecido. Foram realizadas entrevistas com 34 famílias no Brasil e em Portugal. Os entrevistados foram adultos com SD e suas mães. Os resultados mostraram que a rede dos indivíduos com SD é estreita e tem como principal nó a figura materna. As mães são as responsáveis em quase todas as famílias entrevistadas por cuidarem dos filhos com SD, mesmo que para isso tenham que abrir mão de seus momentos de lazer e de suas profissões. Ficou claro que a rede das pessoas com SD é composta principalmente por mulheres e que pessoas de fora da família muitas vezes criam laços negativos com estes indivíduos.
\end{abstract}

Palavras-chave: deficiência; exclusão social; mães; Síndrome de Down; teoria das redes.

\section{Introdução}

No ano de 2014, Portugal et al. publicaram um estudo utilizando a teoria das redes com foco nas teias sociais que a doença mental tece. Nesse seguimento, a pesquisa tem como objetivo principal utilizar a teoria das redes para analisar a configuração das teias sociais de adultos com Síndrome de Down (SD), salvaguardando que a SD não corresponde a um quadro de "doença mental". A teoria das redes permite uma análise relacional que se foca na forma como o indivíduo é condicionado pelo tecido social que o envolve, e como ele também é capaz de modificar este tecido (Hall e Wallman, 1985). Neste estudo busca-se explorar esta potencialidade e analisar a maneira como a pessoa com SD influencia e é influenciada pelos indivíduos que compõem a sua rede. Parte-se de evidências de que a família exerce um papel fundamental em todas as esferas da vida das pessoas com SD (Faria et al., 2016; Hanisch, 2011; Pinto, 2011) e de que a existência de um indivíduo com SD em um núcleo familiar é capaz de impactar sobremaneira a 
história de vida de seus pais e irmãos (Balabanis et al., 2012; Pavia e Mason, 2012; Rodrigues, 2016).

Destaca-se que para realizar um estudo com enfoque na teoria das redes aplicado à realidade das pessoas com deficiência $(\mathrm{PcD})$ é fundamental que se tenha como premissa o modelo social da deficiência, deixando de lado o modelo médico, consagrado por dar luz exclusivamente às limitações físicas, sensórias e cognitivas dos indivíduos com deficiência (Fontes, 2016). Ou seja, é ponto de partida deste estudo que a deficiência não se configura como um atributo do indivíduo, mas antes como resultado de uma complexa interação entre o sujeito e o contexto no qual está inserido (Leitão, 2015). Crooks et al. (2008) acrescentam que compreender o significado social da deficiência simboliza um desafio primordial para pesquisadores de estudos sobre a mesma em qualquer campo do conhecimento.

Ainda que se reconheça a importância de estudos da deficiência com foco no contexto social e não no individual, o mais comum é que se encontrem estudos que, em última instância, atribuem a exclusão vivenciada pelas $\mathrm{PcD}$ a uma fatalidade originada nas características ou inabilidades dessas pessoas. Martins (2005) chama a atenção para o fato de que mesmo em tempos nos quais discussões sobre o corpo são valorizadas por meio, por exemplo, de estudos com foco em questões de género e de raça, não se tem espaço para a problematização da invisibilização social dos corpos das $\mathrm{PcD}$. Para o mesmo autor o elemento biológico individual da deficiência é tomado como motivo suficiente para a compreensão da sua não participação nas atividades centrais da sociedade.

A pesquisa aqui apresentada alinha-se com as propostas das epistemologias do Sul (Santos, 2018). Desenvolvidas a partir da "ideia-chave de que não há justiça global sem justiça cognitiva global” (Santos et al., 2016: 18), as epistemologias do Sul oferecem "uma proposta epistemológica subalterna, insurgente, resistente, alternativa contra um projeto de dominação capitalista, colonialista e patriarcal, que continua a ser hoje um paradigma hegemónico" (ibidem). Martins e Santos (2018) alertam que a dominação constituída pelo capitalismo, pelo colonialismo e pelo heteropatriarcado atua unida e articulada. O presente artigo parte desta premissa como base fundamental para a exclusão social vivenciada pelas pessoas com SD e demais membros das suas redes.

O foco principal do estudo aqui apresentado - assim como na pesquisa de Portugal et al. (2014) - recai nas relações informais existentes nas redes sociais, deixando para segundo plano as relações de rede estabelecidas no âmbito institucional e formal. Sendo assim, foram entrevistadas 34 famílias de pessoas com SD no Brasil e em Portugal. Nas entrevistas buscaram-se 
respostas às perguntas simples e fundamentais colocadas por Portugal (2007a) para sintetizar a análise das redes sociais: Quem faz parte das redes? Quais os conteúdos dos seus fluxos? Quais as normas que regulam a sua ação?

\section{O papel da família nas redes em contextos de exclusão social}

Já em 1957 Bott oferecia um importante contributo para a teoria das redes, ao afirmar que a dinâmica da estrutura familiar depende não apenas do comportamento de seus membros, mas também das relações que estes estabelecem com os outros (Bott, 1976). Esta percepção é fundamental nos estudos relacionados às redes das $\mathrm{PcD}$, uma vez que estas pessoas sofrem um severo processo de exclusão social.

No artigo de Portugal et al. (2014), as trajetórias das pessoas com doença mental revelam que se erguem barreiras na vida cotidiana. As relações não familiares são dominadas pelo estigma da doença e essas pessoas acabam excluídas dos círculos sociais, ficando fechadas nas famílias. Para Portugal (2007b) o parentesco biológico oferece a segurança que os outros laços não comportam, ao mesmo tempo em que impõe obrigações claras.

No que diz respeito às $\mathrm{PcD}$, Martins et al. (2017) alertam que a deficiência se configura como marco de desigualdade e exclusão na sociedade, o que promove a dependência de benefícios sociais e da família por parte destas pessoas. Observa-se que até mesmo as identidades de pais e irmãos são modificadas pela presença de um indivíduo com deficiência na família (Pavia e Mason, 2012). Goffman (2008) enfatiza que o estigma das PcD não se restringe a tais indivíduos - toda a família tende a ser estigmatizada.

Carneiro (2008), em estudo com foco em pessoas com SD, alerta que, mesmo em famílias com recursos financeiros abundantes, é fundamental que exista envolvimento dos familiares para que se forme a rede de apoio necessária para que as pessoas com SD possam se desenvolver fugindo do estereótipo clássico da síndrome. Esta sobrecarga, na visão de Rodrigues (2016), está associada à falta de preparo da sociedade para conviver com PcD.

Dentro das famílias, o cuidado é costumeiramente atribuído às mulheres (Vigano e Laffin, 2019). Não se pode deixar cair no esquecimento que "cuidar" é muito mais do que uma responsabilidade afetiva, é assumir as responsabilidades da comunidade, do Estado, é superar as insuficiências das políticas públicas (D’Ávila, 2019). Fontes (2009) apura em seu estudo que, quando o Estado não cumpre seu papel de promover a inclusão social, muitas funções acabam sendo delegadas às famílias, especialmente às mulheres. Muitas vezes elas assumem sozinhas a criação dos filhos que são abandonados pelos pais (Faria, 2015; Karadag, 2009; Silva e Santos, 2009). 
Diante dessa responsabilidade, diversas são as angústias que tomam conta dessas mulheres, de entre as quais sobrelevam-se o medo das limitações físicas e mentais dos filhos, e o medo da discriminação social (Pinto, 2011). Cabe a ressalva de que o entendimento da mulher como um ser que naturalmente se ocupa de cuidar dos "mais frágeis" tem ampla relação com a linha abissal do patriarcado (Santos, 2018). Este se apoia em uma "base material", a qual se constitui por meio da "apropriação da força de trabalho das mulheres por parte do coletivo dos homens", em um processo que ocorre mediante a exclusão das mulheres dos âmbitos público, político e do mercado, e com sua consequente reclusão aos âmbitos privado e doméstico (Cano, 2016: 50).

\section{O mito do filho perfeito: ser mãe de uma pessoa com deficiência}

$\mathrm{Na}$ esteira da obrigatoriedade social de a mulher ter de desejar ser mãe, vem o mito da mãe perfeita. Mesmo que cada gestação faça parte de um contexto individual, a expectativa social da maternidade como uma vivência ideal é parte de todas as gerações (Rocha et al., 2007). O resultado da busca por atender ao mito da mãe ideal é muitas vezes a culpa materna, que vai se refletir em diversos aspectos da vida dessas mulheres (Lima e Botelho, 2014). Dentro do mesmo raciocínio, a mãe perfeita deve ser capaz de ter um filho perfeito. Muitos são os atores sociais que contribuem para a acentuação desses mitos de perfeição de mãe e filho; entre eles vale destacar o papel das propagandas que exibem exaustivamente a imagem da mãe ideal com seus filhos perfeitos em momentos felizes e livres de problemas (Meneses e Miranda, 2015; Souza, 2017). Na vida real, já desde o nascimento a criança impacta a vida dos pais, que têm de lidar com a cobrança social e com o mito da criança carimbada como sendo de boa qualidade morfológica e genética (Le Breton, 2006). A notícia de que o filho tem alguma deficiência muitas vezes é acompanhada de um processo de negação e de muito sofrimento, principalmente para a mãe. Pinto (2011), ao estudar especificamente indivíduos com SD, nota que além das preocupações com o futuro do filho, a mãe ainda se responsabiliza pela preparação do irmão do indivíduo com $\mathrm{SD}$, de modo que ele possa assumir a responsabilidade de cuidar do seu irmão, no futuro. Para a mãe, a notícia da deficiência do seu filho configura-se como um golpe para a autoestima, resultando em sentimento de culpa (Calvasina et al., 2007). Ao estudar as representações sociais e a SD, Paixão (1997: 144) observou que "a depreciação da criança é sentida pela mãe como uma depreciação de si própria”. Mulheres religiosas aceitam mais facilmente um filho com deficiência, por enxergar tal fato como uma "oportunidade de testemunho de fé ou como uma estratégia de um plano geral de Deus” (Bastos e Deslandes, 2008: 2150). 


\section{O estudo empírico}

As epistemologias do Sul desafiam as epistemologias dominantes, uma vez que se concentram em conhecimentos considerados inexistentes por não serem produzidos de acordo com metodologias aceitáveis ou porque são produzidos por sujeitos ausentes, indivíduos considerados como incapazes de produzir conhecimento válido devido à sua falta de preparo ou mesmo à sua condição não plenamente humana (Santos, 2018). A presente pesquisa alinha-se, portanto, naturalmente, com as epistemologias do Sul na medida em que toma a palavra das pessoas com SD como conhecimento válido, na contramão do senso comum que as coloca como incapazes de terem voz. Desafia-se assim a visão epistemológica dominante que classificaria essas pessoas com base na visão médica da deficiência, como mentes inválidas para a produção de conhecimento. Neste sentido segue-se a recomendação de Cunha (2015), que aponta como primeiro passo para o reconhecimento e a quebra das exclusões promovidas pelas linhas abissais a plena aceitação de que "o outro fala".

Sendo assim, para que a presente pesquisa pudesse prosseguir o seu objetivo, foram entrevistadas presencialmente 34 famílias: 18 no Brasil, entre janeiro e dezembro de 2013, e 16 em Portugal, entre julho de 2018 e maio de 2019. As famílias foram selecionadas por conveniência e utilizou-se o processo de seleção por "bola de neve", isto é, uma família entrevistada indicava outra que potencialmente poderia participar. Foram ouvidas 34 pessoas com SD com idades entre os 17 e os 53 anos e suas mães. Cabe o destaque de que o convite para participar das entrevistas foi feito às famílias, incluindo também os pais - no entanto, nenhum pai se disponibilizou. Este ponto, como será explorado adiante, já parece ser um importante indício da configuração da rede social das pessoas com SD. Os membros da família ampliada não foram contemplados no âmbito deste artigo, mas podem ser importantes para futuras investigações. A principal preocupação da presente pesquisa foi ouvir as pessoas com $\mathrm{SD}$, indivíduos que na maior parte das vezes são silenciados. Para manter a confidencialidade, os sujeitos com $\mathrm{SD}$ entrevistados foram aqui identificados por meio dos codinomes de Filho_01 a Filho_34. Analogamente, as 34 mães entrevistadas receberam os codinomes de Mãe_01 a Mãe_34. É importante frisar que os indivíduos numerados até ao número 18 são parte de famílias que foram entrevistadas no Brasil e os que receberam numeração de 19 até 34 foram ouvidos em Portugal. Acredita-se que foi enriquecedor poder contar com a análise de contextos socioculturais diferentes para ampliar a robustez do estudo. A escolha destes dois países se deu por conveniência, uma vez que a autora do artigo realizou investigação de doutoramento no Brasil e de pós-doutoramento em Portugal. 
A principal técnica de coleta de dados foi a entrevista semiestruturada em profundidade, efetivada com as pessoas com SD e suas mães. Em um artigo sobre as redes socias nos cuidados de pessoas com doenças mentais, Portugal et al. (2014) defendem a utilização de entrevistas em profundidade com famílias e focadas em suas histórias de vida para qualquer pesquisa interessada nas relações em rede. Também se seguiu a recomendação destes autores no que diz respeito à utilização do método "bola de neve" para conseguir entrevistados. As entrevistas compreenderam três instâncias: 1) narrativas da história de vida das mães e dos indivíduos com SD; 2) apresentação e descrição de fotografias, procedimento nomeado "álbum de família"; e 3) aplicação de técnicas projetivas com o uso de imagens e textos para complementação de histórias. Todo o material empírico obtido nas entrevistas foi tratado por análise de conteúdo (Bardin, 2011), seguindo três procedimentos: leitura crítica; exame e avaliação do conteúdo das transcrições; e classificação de termos e ideias. A seguir é apresentado um quadro sintético (Quadro 1) que teve como objetivo auxiliar o desenvolvimento da análise dos resultados.

\section{QUADRO 1 - Quadro síntese para a análise dos resultados}

\begin{tabular}{ll}
\hline Nós da rede & Principais características \\
\hline Outras pessoas com SD & Laços positivos (muitas vezes impostos) \\
\hline \multirow{2}{*}{ Mães } & $\begin{array}{l}\text { Principal elemento da rede (por vezes } \\
\text { único); } \\
\text { Vida atrelada à do filho com SD; } \\
\text { Identidade modificada }\end{array}$ \\
\hline & Laços fracos; \\
Pais & Relatos de rejeição; \\
& Pouca (ou nenhuma) participação em \\
& cuidados diários \\
\hline \multirow{3}{*}{ Irmãos (principalmente irmãs) } & Responsáveis pelos irmãos com SD no \\
& futuro; \\
& Laços positivos mais fortes na infância \\
\hline & Laços fracos (ainda que mais fortes do que \\
& os dos homens da família alargada); \\
Mulheres da família alargada (tias, avós) & Responsáveis por cobrar as mães; \\
& Laços negativos muito marcantes em \\
& alguns casos \\
\hline Outros (colegas, vizinhos) & Laços predominantemente negativos; \\
& Tentativa de distinção \\
\hline
\end{tabular}




\section{Apresentação e análise dos resultados}

As estruturas sociais básicas da teoria das redes podem ser representadas por "laços" e "nós" (Wellman e Berkowitz, 1991). Os resultados serão apresentados levando em consideração os nós (pessoas) e os laços (relação entre os nós) da teia das pessoas com SD.

As entrevistas mostram que as redes das pessoas com SD tendem a ser constituídas por poucos nós. Os entrevistados com SD deixaram claro que reconhecem poucas pessoas como indivíduos que de fato estão presentes em seu convívio diário. Deste principal e amplo achado advém a afirmação do título desta comunicação de pesquisa: "As teias que a Síndrome de Down não tece”. Cabe a ressalva de que em nenhum momento este título tem a intenção de culpar o indivíduo com SD pela restrição de suas teias. O alinhamento da pesquisa com as epistemologias do Sul e a negação da perspectiva médica da deficiência já enunciadas anteriormente reforçam a importância de se enfatizar que a condição de exclusão social vivenciada pelas pessoas com $\mathrm{SD}$ e suas famílias (especialmente suas mães) é resultado de barreiras das mais diversas naturezas impostas pela sociedade.

Relativamente aos laços, os positivos são de aproximação e os negativos de distinção (Portugal et al., 2014). É interessante notar que existe para as pessoas com SD um laço de aproximação mandatório com relação a outras pessoas que têm a mesma síndrome - algo como uma obrigação socialmente imposta de serem próximos e criarem laços positivos com essas pessoas unicamente por terem a mesma síndrome. No entanto, foram sobretudo apurados diversos laços negativos. Segundo os entrevistados, a generalidade das pessoas - que compõem ou não a rede dos indivíduos com SD - apresentam comportamentos de busca por distinção com relação a indivíduos com SD. Esse é mais um achado da pesquisa no sentido de mostrar que a exclusão social das $\mathrm{PcD}$ passa principalmente pelos rótulos do "nós" e dos "outros". Rótulos estes que colocam, em última instância, as PcD na condição de "sub-humanos".

Outra questão fundamental da teoria das redes são as normas que dizem respeito a como os indivíduos devem comportar-se. São essas normas que ditam o que esperar dos outros, reduzindo assim as incertezas dos membros da rede (Portugal, 2007b). A questão pode ficar mais complexa quando um dos atores foge da norma. O comportamento de uma pessoa com deficiência intelectual pode fugir destas normas em alguns casos, fazendo com que os outros não saibam como lidar com esses indivíduos. A não abertura da sociedade a pessoas que não assumam comportamentos completamente dentro da norma é mais um fator responsável pela exclusão social. 


\subsection{O mais importante dos nós: as mães}

$\mathrm{Na}$ presente pesquisa ficou bastante claro que as mães constituem o principal, quando não o único, nó da rede de seus filhos com SD. Em seu trabalho com relação às teias das pessoas com doenças mentais, Portugal et al. (2014) também já haviam apontado que são as mães as pessoas mais importantes da teia desses doentes. A similaridade dos achados desses dois estudos no que constitui o papel das mães aponta para a confirmação de que elas assumem um lugar central nas teias de seus filhos, independentemente do tipo ou da natureza dos cuidados e atenções que estes necessitam. Diversas narrativas das participantes desta pesquisa tratam o cuidado como um papel somente materno, naturalizando a questão do gênero como fundamental para a designação de deveres na família da PcD.

Sabe como é [...] cuidar é muito mais feminino. Então fica mesmo com a mãe, isso do Down. (Mãe_02)

Não culpo o meu marido. Rapazes não são mesmo de cuidar, ensinar [a] portar-se. Isso fica conosco [mães]. (Mãe_23)

A centralidade da mãe na teia do filho com SD também tem como característica o fato de serem elas as únicas presentes durante toda a vida desse indivíduo. Algumas outras pessoas, nomeadamente pais e irmãos, até podem ser importantes em algum momento, mas são as mães as personagens centrais na respetiva história de vida. Muitos depoimentos mostraram que as mães se creem as únicas responsáveis pelo filho com SD e não consideram dividir tarefas com outras pessoas.

A partir do momento que eles [os irmãos] começaram a sair à noite, é muito raro eu pedir para ficar com ela para eu sair, entendeu? Porque você acostuma, você acha assim: não... é meu, eu [a] tenho, então eu que cuido, ninguém tem que ficar [com ela], ninguém tem que, entendeu? Aí você acostuma, né. Tudo é com a mãe. 100\% responsável pelo Down. (Mãe_01)

Essa relação entre mãe e filho parece ser tão intensa que provoca mudanças na identidade dessas mulheres. Uma delas sintetizou essa questão, dizendo: "Quem eu sou? A mãe do [Filho_06]" (Mãe_06). E acrescentou "nada na minha vida ocorre sem que eu carregue esse rótulo". Essa postura tem relação direta com a imposição social de que toda a mulher tem que ser uma mãe impecável (Dourado e Pelloso, 2007; Piccinini et al., 2008). A mistura da identidade da mãe com a do filho é incentivada socialmente 
(Barbosa e Rocha-Coutinho, 2007), e para as mães das pessoas com SD isso envolve absorver o estigma da deficiência.

O Quadro 2 sintetiza, a partir de depoimentos espontâneos nas entrevistas, aspectos que parecem ser marcantes na identidade da mãe de um filho com SD:

QUADRO 2 - Identidade da mãe de uma pessoa com Síndrome de Down

\begin{tabular}{l}
\hline Ser mãe de uma pessoa com SD é... \\
...ter um filho eternamente criança \\
...abrir mão de alguns tipos de produtos e serviços \\
...não ser dona de seu tempo \\
...consumir o que o filho consome \\
....assumir toda a responsabilidade do cuidado com o filho \\
...gostar do que o filho gosta \\
.... decidir pelo filho \\
....querer ser imortal para cuidar da eterna criança
\end{tabular}

Fonte: elaboração da autora com base na análise dos resultados desta pesquisa.

Muitas das mães participantes da pesquisa relataram que já ouviram de pessoas próximas, amigos e familiares que elas não podem reclamar de terem de cuidar dos filhos com SD, porque são responsáveis pela deficiência. Essa pressão social faz com que aumente nessas mulheres o sentimento de culpa por, supostamente, não corresponderem aos mitos da mãe perfeita e do filho perfeito. Calvasina et al. (2007) e Paixão (1997) já haviam apontado a culpa como um sentimento muito nocivo e presente nas vidas das mães de uma PcD. No presente estudo, essa culpa apareceu muitas vezes relacionada à religião. Para as mães que se disseram muito religiosas, os filhos com deficiência são um sinal de falha no passado ou uma forma de comprovarem a sua fé.

Os meus pais me expulsaram de casa quando souberam que o meu filho era Down. Falaram que a culpa era minha. Desde aquele momento passei a me culpar pela deficiência dele. (Mãe_34)

A culpa e o fato de serem as responsáveis pelos seus filhos muitas vezes fazem com que as pessoas com SD sejam muito dependentes de suas mães. Alguns depoimentos tinham presente o discurso de que existe a busca pela 
independência do filho com SD para que ele possa se descolar da figura da mãe. Cabe a ressalva de que a análise das entrevistas revela que, muitas vezes, essa dita vontade não parece se concretizar em ações que de fato poderiam dar mais autonomia para essas pessoas. Os sujeitos com SD entrevistados demonstraram ansiar por mais independência. O entrevistado Filho_04, por exemplo, revelou que gostou do filme Colegas, ${ }^{1}$ porque a história de ficção retratou os indivíduos com SD como seres independentes de suas mães. A entrevistada Filho_11 também demonstrou vontade de não ser tão dependente da mãe e perguntou diversas vezes para a entrevistadora: "Porque os meus irmãos saem sem ela e eu não?”. Diante da falta de perspectiva de que diminua com o tempo a dependência dos filhos, algumas das mães entrevistadas contaram que se preocupam em dividir o tempo entre o que querem e as vontades dos filhos com SD.

Então, como eu sou uma pessoa [...] divorciada e [com] os filhos já casados, meu sábado é dele. Sábado é dele. Domingo é meu. Tenho que ter um dia, senão vou ter um troço. Sábado é dedicado a ele. Sábado eu faço o que ele quer, domingo o comando é meu. (Mãe_06)

Foi possível perceber que a tentativa de equilíbrio do tempo despendido com o filho com SD e com suas próprias demandas é mais bem-sucedida no caso de mães que têm uma ocupação profissional. A literatura revista havia descrito essa mesma relação no caso de pessoas com deficiência visual (Balabanis et al., 2012). Algumas mães que não desempenham atividades profissionais - muitas vezes até mesmo por causa do indivíduo com SD demonstraram vivenciar mais o estigma da deficiência. Goffman (2008) já havia defendido que a mãe muitas vezes é estigmatizada tanto quanto a $\mathrm{PcD}$. Para essas mulheres, a identidade que tinham antes do filho nascer estava atrelada ao trabalho que desempenhavam e agora sua tarefa principal na família e na sociedade é cuidar - para utilizar palavras de uma das entrevistadas que parou de desempenhar a sua atividade profissional depois do nascimento do filho com SD. Alguns relatos também deram conta de mães que modificaram sua trajetória profissional, se aproximando de áreas como a educação inclusiva para ajudarem na inclusão social de seus filhos. Também existiram mães que disseram que "agora a vida é militância pela inclusão das pessoas com Síndrome de Down” (Mãe_32). Se o filho com SD tem impacto no papel social das mães como trabalhadoras, também modifica essas mulheres no que tange às suas escolhas de lazer.

${ }^{1}$ Galvão, Marcelo (2012), Colegas. Gatacine. 
Viajei sem ele. Que dó, que peso! Deixa com sentimento de culpa. Porque mal ou bem ele depende de mim para se divertir. Não é como uma pessoa da idade dele que pega e viaja com os amigos. (Mãe_11)

É bastante assim, se você perguntar para uma mãe de uma pessoa com deficiência o que ela gosta, pode ter certeza, assim de coisa de lazer, muito do que ela vai te falar tem relação com o que o filho gosta. (Mãe_01)

No que diz respeito ao rótulo das $\mathrm{PcD}$ como consumidores inaptos ou vulneráveis (Faria e Casotti, 2017), apurou-se acentuada dependência dos indivíduos com $\mathrm{SD}$ com relação a suas mães no que diz respeito às suas escolhas de consumo, até mesmo para decisões simples, como o consumo de alimentos.

Gosto de tomar açaí, mas ela não gosta, então não vou [tomar]. Ela [é] que tem dinheiro. (Filho_15)

Eu não gosto de maçã. Mãe não gosta. Então eu não gosto. Ela [é] que compra. Ela decide. (Filho_02)

Esse controle com relação às escolhas dos filhos está diretamente relacionado à visão das pessoas com SD como crianças, mesmo quando estas já são adultas. Os relatos mostram que as mães fazem a comparação de seus filhos com SD com crianças e relatam que a diferença básica é que, no caso dos sujeitos com $\mathrm{SD}$, não há perspectiva de que a dependência diminua com o tempo e, por esse mesmo fato, parece não fazer sentido tentar ensinar noções importantes para que essas pessoas tornem-se decisoras com respeito às suas próprias escolhas de consumo.

Não é que ele não goste de escolher o que vai comprar. É assim: é porque não incentiva desde pequenininho. Qualquer criança é incentivada desde pequena a escolher algumas coisas que goste, tipo de comer, de fazer nas férias, roupa. O Down não... é como se todas essas escolhas, no caso deles, tivessem que ficar com os pais. O que é ruim tanto para eles quanto para os pais, porque para os pais é uma reponsabilidade e tanto. (Mãe_11)

A visão dos filhos como eternas crianças foi quase unânime entre as mães entrevistadas. Cabe a ressalva de que todas tinham filhos com SD adultos e, ainda assim, ao falarem sobre eles a utilização de palavras como "criança" e "miúdo/a" era muito recorrente. Esse sentimento/percepção de que os filhos 
não vão crescer parece deixar essas mulheres muito angustiadas. Algumas disseram, por exemplo, que sonham com o dia no qual elas poderão escolher as coisas que querem fazer, sem pensar primeiro nas necessidades dos filhos. Essas mesmas entrevistadas admitiram saber que esse dia nunca vai chegar. Segundo elas, a gradual aquisição de independência que geralmente os filhos conquistam não ocorre com os filhos que têm SD.

Uma das angústias mais recorrentes a respeito dessa vida de eterna criança dos filhos é o fato de que um dia elas, mães, irão morrer. Guiadas por este pensamento, algumas mulheres buscam tornar seus filhos o mais independentes possível. Elas reconhecem que é um caminho difícil, mas asseguram que não desistem porque sabem que um dia morrerão e qualquer que seja a pessoa que vai assumir a responsabilidade pelo filho com SD não terá tanta disponibilidade como elas. Cabe o importante destaque de que, mesmo nesses casos, ou principalmente neles, as mulheres dedicam seu tempo e seus recursos financeiros aos filhos.

A busca pela independência dele para mim sempre foi palavra de ordem. Faço qualquer coisa para isso. Dedico a maior parte do meu tempo a isso. (Mãe_12)

As entrevistas em Portugal revelaram outra questão relacionada com a preocupação de o que vai acontecer com os indivíduos com SD quando suas mães morrerem. Diferentemente do que ocorre no Brasil, em Portugal os lares para $\mathrm{PcD}$ são uma realidade presente. Diante dessa possibilidade, as mulheres entrevistadas nesse país disseram que existe um grande julgamento social para as famílias que optam por colocar as $\mathrm{PcD}$ em lares. Este julgamento recai principalmente sobre as mães que, "segundo os olhos da sociedade, estariam abandonando seus miúdos" (Mãe_27). Diante dessa visão negativa da sociedade, a maioria das mães entrevistadas disse que não pensa na possibilidade do lar, mas algumas lamentaram a hipótese provável de que esta seja a única opção em uma dada altura.

Todo mundo julga. É abandono [colocar no lar]. (Mãe_20)

Infelizmente, como não tenho outros filhos, penso no lar, sim. E quando eu morrer? Quem fica com ela? (Mãe_31)

Em suma, é preciso deixar claro que essas mulheres, mães de pessoas com SD, configuram-se como o principal nó da rede de seus filhos - não sem impactos nas suas identidades e nas suas histórias de vida. É urgente visibilizar essas mulheres e suas histórias, e para isso é fundamental a 
prevalência do modelo social da deficiência. Estudos e movimentos sociais interseccionais precisam dar conta das identidades dessas mulheres sob a ótica da exclusão promovida pelo patriarcado e pelo estigma da deficiência.

\subsection{Irmãos e "futuros pais"}

Ao olhar para os outros nós da rede das pessoas com SD, mais uma vez percebemos a mãe como pessoa central, inclusive no que diz respeito a "ensinar" os outros componentes da rede como eles devem desempenhar seus papéis. No caso dos irmãos de indivíduos com SD, essa configuração é clara e está presente na maioria das famílias ouvidas por esta investigação. Pinto (2011) já havia apontado essa função das mães de elucidar os deveres dos irmãos (das pessoas com SD).

A primeira questão com relação à participação dos irmãos nas redes das pessoas com SD que deve ser apresentada é o fato que muitas mulheres declaram que desejaram ter outro(s) filho(s) principalmente para que estes pudessem ficar responsáveis pelos indivíduos com SD quando elas morressem. Ou seja, existem indivíduos que já nascem com a tarefa de cuidar dos seus irmãos com SD. Isso faz com que as identidades dessas pessoas sejam intimamente relacionadas com esse papel que se espera que desempenhem.

Eu quis sim ter outros filhos depois que ele nasceu. Precisava de uma, na verdade mais do que uma pessoa para cuidar dele quando eu não puder mais. (Mãe_05)

Eu gosto do meu irmão. Ele é mais novo do que eu. Um dia eu vou morar com ele. Eu sou o mais velho. (Filho_31)

O último depoimento demonstra que uma pessoa com SD, identificada aqui como Filho_31, tem consciência de que, mesmo ele sendo mais velho, um dia ele irá ser cuidado pelo irmão. Em muitas entrevistas, os indivíduos com SD mostraram-se desconfortáveis por terem de aceitar as regras e os comandos dos irmãos, principalmente nos casos em que a pessoa com SD é o filho mais velho. Nota-se, ainda que não se tenha entrevistado os irmãos, que as relações entre eles também são pautadas na visão da pessoa com SD como eterna criança.

A mana é 10 anos mais nova do que ele, mas ele é o bebé da mana. Se calhar é assim mesmo que é melhor. (Mãe_20)

A despeito desta designação - por vezes aberta, por vezes oculta - de que os irmãos um dia serão responsáveis pelas pessoas com SD, existe uma fase 
de suas vidas, nomeadamente a adolescência, na qual ocorre um distanciamento. Nesse momento, o nó "irmão", que é muito importante na infância da criança com SD e que vai voltar a ser importante na vida adulta, perde a força na rede dos indivíduos com SD.

Os irmãos brincam na infância, mas depois vão viver a vida deles. (Mãe_10)

Quando os irmãos começaram a namorar, pronto, ele ficou para depois. (Mãe_15)

A vivência por parte dos irmãos de rituais de passagem importantes, principalmente a entrada para o ensino superior e o início de relacionamentos amorosos, é bastante significativo para mudanças na relação entre e com os indivíduos com SD. Rook (1985) pondera sobre a importância dos rituais de passagem na vida de uma pessoa. Os grandes ritos de passagem marcam transições de status social, estimulam grande envolvimento psicológico e provocam forte ansiedade. Para Fournier (2008), a participação de PcD como protagonistas em rituais de passagem parece ser desestimulada por seus pais - e irmãos, acrescentaria ainda a autora desta pesquisa -, que veem os indivíduos com SD como eternas crianças. Corroborando a visão destes autores, a presente pesquisa aponta que muitas famílias desencorajam ou mesmo impedem que as pessoas com SD protagonizem rituais de passagem. Este impedimento pode ser visto como uma das causas do rótulo dessas pessoas como eternas crianças, e como um dos motivos do afastamento entre o indivíduo com SD e os seus irmãos na adolescência.

Quando os irmãos estão adultos, e principalmente quando já têm filhos, parece ocorrer uma reaproximação entre eles e o seu irmão com SD. Muitos entrevistados relataram ter uma ótima convivência com os sobrinhos e muitas mães declararam que veem a chegada da nova geração como uma forma de reaproximar o membro da família com SD dos irmãos. Apesar de aparentemente positiva, essa reaproximação também parece funcionar como um reforço para a permanência do indivíduo com SD como criança. Com o nascimento dos sobrinhos, essas pessoas passam a serem tratadas pela família alargada como pertencente à geração mais jovem e isso condiciona principalmente suas atividades de lazer.

Também no que diz respeito a atividades de lazer, algumas mães apontaram que os irmãos não costumam convidar os indivíduos com SD a participar nas mesmas, e atribuíram este fato à rejeição por parte dos amigos dos irmãos, que não aceitam bem a presença da $\mathrm{PcD}$. Segundo elas, é difícil haver o acolhimento do indivíduo com SD em momentos de lazer por parte de pessoas que não têm $\mathrm{PcD}$ nas suas famílias. Essa situação relatada é mais 
um indício de que a rede das pessoas com SD está muito restrita ao seio familiar, e também com pessoas de fora da família, sendo ambos vistos como responsáveis pela manutenção e acentuação da exclusão social.

Nesses anos todinhos, ela chamou a irmã [Filho_08] para ir duas vezes a algum lugar, a irmã. E essa coisa, ela adora. Ela adora por quê? Está doida para sair de perto da mãe, que ela não aguenta mais essa companhia. (Mãe_08)

Os outros, amigos e tal, não gostam que ele leve o irmão deficiente, [então] ele não leva. (Mãe_29)

Cabe a ressalva de que, na relação entre os indivíduos com SD e seus irmãos, os estereótipos de gênero estão muito presentes. Assim como são as mães as principais responsáveis por cuidar dos filhos com SD, as irmãs são vistas como "naturalmente mais afeitas ao cuidado [do que os irmãos]" (Mãe_29). Algumas mães entrevistadas disseram que lamentam só ter tido filhos homens, por acreditarem que isso dificulta que algum dos irmãos assuma de fato o cuidado do irmão com SD quando elas morrerem. Um dos depoimentos foi bastante marcante neste sentido.

Como só tenho rapazes, agora fico na torcida para que um deles se case com uma rapariga boa que cuide do meu [Filho_31]. (Mãe_31)

Todas essas análises, principalmente quando conjugadas com as que serão apresentadas na próxima seção, desenham a rede das pessoas com SD como sendo composta principalmente, quando não unicamente, por mulheres. São mães, irmãs e até mesmo cunhadas que assumem como responsabilidade sua o cuidado desses indivíduos que a sociedade exclui e classifica como eternamente dependentes. É impossível verificar essa configuração sem fazer referência à linha abissal do patriarcado (Santos, 2018) que, ao determinar o que se espera socialmente de uma mulher, lhes impõe, por exemplo, a tarefa de cuidadoras dos mais vulneráveis, mesmo que essa tarefa signifique que elas devem abrir mão de outros papéis sociais que gostariam de desempenhar (Fontes e Martins, 2015).

Tudo o que foi aqui analisado sobre a presença do irmão na rede do indivíduo com SD leva a questão de que se espera desse irmão, principalmente se for uma irmã, que ela corresponda ao mito do filho perfeito (ver Le Breton, 2006). Além de ter de suprir os anseios dos pais sobre um filho idealizado que não se concretizaram no caso do filho com SD, eles ainda têm de assumir o compromisso de cuidar dos irmãos no futuro. Diante dessas pressões, 
foi recorrente ouvir relatos de mães que descrevem o filho cuidador como perfeito e outros relatos de irmãos que buscaram alternativas, nomeadamente mudando-se para outro país, no intuito, mesmo que velado, de não terem de assumir a responsabilidade do cuidado do irmão com SD.

\subsection{Narrativas sobre a ausência da figura paterna}

Inicialmente, antes mesmo da análise sobre o papel do pai na rede das pessoas com $\mathrm{SD}$, é preciso lembrar que, assim como foi explicado na seção que apresentou os procedimentos metodológicos seguidos na pesquisa, os pais não foram entrevistados para essa investigação. Em outras palavras, as análises aqui apresentadas baseiam-se, para além da revisão de literatura realizada, nos depoimentos das mães e dos indivíduos com SD. Essa observação não tem, de maneira alguma, a intenção de diminuir os achados aqui apresentados. Ao inverso disso, teve-se a oportunidade de dar voz a pessoas que costumeiramente são silenciadas, o que é capaz de apresentar o ponto de vista dos excluídos, assim como preconizam as epistemologias do Sul (Santos, 2018).

Voltando à análise da rede das pessoas com SD, é importante notar a ausência da figura paterna em muitas delas. As não presenças físicas mais relevantes ficam por conta dos casos nos quais: 1) o casal se separou e o pai não mantém contato com o filho com SD; e 2) os pais já faleceram. Entretanto, o que chama mais a atenção são os casos nos quais o pai mora na mesma casa do indivíduo com SD, mas assume bem menos, ou até nenhuma, responsabilidade no dia a dia dos filhos, se comparado com a que é assumida pela mãe. Independentemente do motivo, é importante enfatizar que a falta do pai na hierarquia familiar faz com que as mães assumam totalmente a criação dos filhos e/ou que os irmãos tenham maior importância e, em alguns casos, até mesmo assumam um papel com responsabilidades e autoridade que em geral não são inerentes à relação fraternal.

Vários depoimentos das famílias revelavam histórias de homens que, nas palavras das entrevistadas, "fogem", "não seguram" ou "não assumem" o filho com SD e deixam as mulheres como únicas responsáveis pelos filhos quando eles ainda são crianças. A revisão de literatura já havia apontado essa possibilidade quando foram revisitados estudos como o de Karadag (2009), no qual fica patente que a exclusão muitas vezes ocorre por parte da própria família, e que, nesses casos, a PcD passa a contar somente com a mãe. Alguns dos depoimentos chegam a tratar esse abandono por parte das figuras masculinas como uma simples questão de gênero. Tudo acaba funcionando de forma naturalizada, como se as mulheres tivessem mais obrigação do que os homens de cuidar dos filhos com SD. D’Ávila (2019) já havia 
apontado que a determinação social de que o cuidar é da responsabilidade somente das mulheres é extremamente nocivo e baliza muito as relações entre homens e mulheres, principalmente quando estes são pais e mães.

[...] sempre a mãe ou a avó, a irmã, uma figura feminina. Os homens não seguram. Essa rotina é do Down com a figura feminina. É instinto mesmo. O homem não está disposto a abrir mão da liberdade dele. (Mãe_03)

Comigo não foi assim, o pai é muito parceiro, mas sei que normalmente não é assim. (Mãe_34)

O último depoimento é um exemplo do que foi repetido pelas entrevistadas que disseram ter "todo o apoio dos pais" e se referiram a essa situação como uma "questão de sorte". Mesmo essas mulheres disseram que conhecem várias famílias nas quais a situação é diferente da delas. Nas entrevistas com essas mães, foi possível perceber que realmente existe uma importante participação dos pais na rede desses filhos com SD, ainda que, em muitos casos, a mãe é que é responsável por levar e buscar nas atividades diárias, por tomar escolhas importantes na vida dos filhos e por abrir mão de seu emprego/ocupação para se dedicar à rotina do filho.

Os depoimentos dos indivíduos com SD demonstraram que eles sentem falta da figura paterna. Eles reconhecem que são as mães as pessoas que mais se encarregam de suas atividades diárias e as têm como principal figura de referência.

O pai não me leva cá [sic] para o basquete. (Filho_19)

O pai fica a trabalhar [...] a mamã [es]tá sempre comigo. (Filho_23)

Nas famílias nas quais o pai se faz mais presente foi possível perceber que este ocupa lugar de destaque na rede do indivíduo com SD. Nos casos desses pais, também eles carregam o estigma da deficiência, ainda que de maneira diferente da vivenciada pelas mães. Pode-se atribuir essa diferença principalmente à crença social de que a mulher tem de ser a mãe perfeita, não sendo o mesmo cobrado aos pais (D’Ávila, 2019; Lima e Botelho, 2014).

\subsection{Família alargada e os outros}

Em um artigo sobre as redes sociais, Portugal (2007b) ressalta que no caso português é muito forte o senso de responsabilidade que determina que a família tem a obrigação de cuidar dos seus. Na presente pesquisa foi possível 
perceber, ainda que não fosse o objetivo traçar comparações, que as famílias alargadas portuguesas - nomeadamente avós e tias - têm maior participação na rede dos indivíduos com SD do que as brasileiras.

Cabe a ressalva de que, acompanhada dessa maior participação da família alargada, parece existir uma maior cobrança de responsabilidades da mãe. Em outras palavras, a família alargada está mais presente na rede dos indivíduos com $\mathrm{SD}$, possui laços positivos, mas essa presença é acompanhada de julgamentos e palpites sobre o que a mãe deve fazer pelo seu filho.

A minha mãe é muito presente. Ajuda com ela desde que nasceu, mas também julga. Fala mesmo. E me cobra. (Mãe_31)

Entre as pessoas da família alargada, mais uma vez percebe-se o protagonismo das figuras femininas. Em outras palavras, são as avós, primas e tias que estão mais presentes nas redes dos indivíduos com SD, se comparado com os familiares do sexo masculino.

$\mathrm{Na}$ contramão dessa maior participação da família alargada entre os entrevistados residentes em Portugal, também foi no relato deles que foram escutadas as principais histórias de vida evidenciando afastamento imediato da família alargada após o nascimento do bebê com SD.

Eu era muito próxima à minha mãe. Depois de ele nascer ela sumiu. Tem vergonha, se calhar. (Mãe_26)

Quando o meu filho nasceu, os meus pais falaram que eu até poderia ficar na casa deles, mas o meu filho ficaria no estábulo, que era o lugar para pessoas como ele [...]. Quando a minha mãe morreu, eu não fui no enterro. (Mãe_19)

O último depoimento demonstra que a família alargada pode ter laços negativos muito marcantes na rede do indivíduo com SD. Diversos outros depoimentos demonstraram a criação de laços negativos, de diferenciação, por parte de avós, tios, primos e outros familiares. Mesmo dentro da família, as pessoas com $\mathrm{SD}$ e suas mães são estigmatizadas, o que faz com que esses elementos da família alargada muitas vezes nem se configurem como nós da rede dos indivíduos com SD.

Quando o foco passa para os "outros", ou seja, pessoas que não fazem parte da família, como amigos, colegas e vizinhos, os laços negativos ficam ainda mais óbvios. Vale lembrar que os laços negativos buscam a diferenciação (Portugal et al., 2014). Essa tentativa por parte da sociedade em 
geral de reafirmar constantemente que as pessoas com SD são diferentes, fica muito clara para os entrevistados.

Aquele vizinho não gosta de mim porque sou Down [...], sou diferente. (Filho_05)

Os meus amigos são Downs. Esses aqui [da mesma instituição]. (Filho_27)

O último depoimento ilustra uma configuração bastante comum no que diz respeito à presença de amigos nas redes do indivíduo com SD. A grande maioria dos amigos também têm $\mathrm{SD}$ e as instituições são muitas vezes o laço que une essas pessoas. Num estudo com pessoas com doença mental, Portugal et al. (2014) mostraram que essas pessoas criam muitos laços nos hospitais e, no caso dos indivíduos com $\mathrm{SD}$, as instituições parecem ser as responsáveis por, de certa forma, promoverem as amizades. Não se pode deixar de observar que quase todos os entrevistados frequentaram, em algum momento de sua infância, ambientes escolares, mas não citaram esses espaços de educação formal como especialmente importantes na sua rede de amigos. Já as mães entrevistadas lembram-se de momentos nos quais seus filhos sofreram preconceito e foram excluídos nos ambientes escolares.

Os miúdos não gostavam dele. Mesmo ele se portando bem, não tinha amigos. (Mãe_26)

Os achados desta investigação também vão ao encontro do entendimento de Portugal et al. (2014) de que os outros se relacionam com o estigma e não com a pessoa. No caso dos indivíduos com $\mathrm{SD}$, ficou claro que o fato de ser uma deficiência visível e facilmente identificável pelo fenótipo faz com que, mesmo num primeiro contato, a relação dos outros com eles passe por rótulos socialmente tecidos e quase nunca correspondentes à realidade.

Em resumo, quando se fala desses dois grupos de pessoas, nomeadamente a família extensa e os outros, o que se percebe é a sua pouca presença nas redes das pessoas com SD. Essas ausências, ou presenças marcadas por laços negativos, parecem ser largamente responsáveis pela exclusão social dos indivíduos com SD. Cabe a reflexão sobre esse achado à luz do que escreve Bourdieu (2011) quando fala em capital social. Este autor está centrado no que a rede social pode trazer para o indivíduo. A definição de "capital social" de Bourdieu passa pela percepção do conjunto de recursos efetivos ou potenciais relacionados à existência de uma rede social durável de interconhecimento e de reconhecimento. No caso das pessoas com SD, de acordo com os achados desta pesquisa, pode-se afirmar que a falta de 
uma rede ampla prejudica inclusive a possibilidade de acumulação de capital social por estas pessoas.

\section{Considerações finais}

O estudo mostrou que a rede social das pessoas com SD está muitas vezes restrita à família e centralizada na figura materna. Ficou claro que a visão preconizada pela dominação do patriarcado, de que o cuidado é função das mulheres, é extremamente marcante e nociva na história de formação das redes dos indivíduos com SD. Não é exagero afirmar que, em muitos casos, o fato de ter um filho com SD modifica e molda completamente a identidade dessas mulheres, que são julgadas, estigmatizadas e invisibilizadas socialmente. Cabe a ressalva de que ter a mãe como a única responsável pelo indivíduo com SD é cômodo para a lógica social de exclusão. Essas mulheres assumem, na maioria das vezes de forma naturalizada, papéis que deveriam ser desempenhados pelo Estado, pelas organizações privadas e pela sociedade em geral. Em outras palavras, é útil socialmente - principalmente no que tange à lógica capitalista -, manter os indivíduos com SD em posição de vulnerabilidade e suas histórias como tragédias individuais, para que nada tenha de ser feito fora de suas estreitas redes no sentido de prover a inclusão social. Essa afirmação decorre da visão de que, segundo os entrevistados, as pessoas com SD são vistas como indivíduos improdutivos e, portanto, descartáveis dentro do sistema capitalista. Seguindo a visão de Castel (2011), as pessoas com SD parecem configurar um exemplo fiel da ruptura mais expressiva da exclusão, já que estas pessoas não estão incluídas no mercado de trabalho e, em muitos casos, não podem contar nem mesmo com seus parentes próximos nas suas redes sociais.

No que diz respeito ao momento de desinstitucionalização pelo qual estão passando os dois países nos quais a pesquisa foi realizada, Brasil e Portugal, é preciso lembrar que se não houver informação, educação, democratização e políticas públicas eficazes, esse processo tende a acentuar a dependência que as $\mathrm{PcD}$ têm relativamente às suas mães. Uma vez que, conforme indicaram os resultados da pesquisa, especialmente em situações de desamparo social, as mães são levadas a assumir, de forma quase compulsória e naturalizada, a responsabilidade de cuidarem de seus filhos com SD. Essa responsabilidade é ainda mais preocupante quando se percebe que o fluxo entre o indivíduo com SD e a sua mãe não envolve somente afeto e cuidados básicos, mas também dependência financeira.

A rede dos indivíduos com SD se mostrou quase que exclusivamente composta por mulheres e evidenciou que, quando se trata de figuras masculinas, os laços biológicos não parecem ser suficientes para mantê-los como 
nós presentes na rede. Diante de tudo o que foi exposto, fica a certeza de que é preciso que sejam realizadas mais investigações que coloquem em foco a questão do gênero no que toca à deficiência. São muito importantes estudos interseccionais que tragam para o debate questões relativas a estas mulheres - principalmente mães, mas também irmãs, tias e avós - que são excluídas pelo machismo e pelo estigma alargado da deficiência.

Igualmente urgentes são estudos que foquem em questões que passam pelo ponto central: a quem serve a lógica da exclusão? Não é suficiente apontar que as redes dos indivíduos com SD são moldadas pelo estigma e pela configuração social excludente, é preciso questionar academicamente quais são os agentes que se beneficiam da manutenção da exclusão. Acredita-se, com base nesta e em pesquisas anteriores (Faria e Casotti, 2019), que existe um proposital desinteresse do poder público, das empresas privadas e mesmo das organizações do terceiro setor em atender as necessidades e desejos das pessoas com SD. Este desinteresse, enraizado na lógica capitalista, deve ser exaustivamente pauta de futuras pesquisas.

Revisto por Alina Timóteo

\section{Referências bibliográficas}

Balabanis, George; Mitchell, Vicent; Bruce, Ian; Riefler, Petra (2012), “A Conceptual Stress-Coping Model of Factors Influencing Marketplace Engagement of Visually Impaired Consumers”, Journal of Consumer Affairs, 46(3), 485-505.

Barbosa, Patrícia; Rocha-Coutinho, Maria Lúcia (2007), "Maternidade: novas possibilidades, antigas visões”, Psicologia Clínica, 19(1), 163-185.

Bardin, Laurence (2011), Análise de conteúdo. Lisboa: Edições 70.

Bastos, Olga; Deslandes, Suely (2008), "A experiência de ter um filho com deficiência mental: narrativas de mães”, Cadernos de Saúde Pública, 24(9), 2141-2150.

Bott, Elizabeth (1976), Família e rede social. Rio de Janeiro: Livraria Francisco Alves. Tradução de Mário Guerreiro [orig. 1957].

Bourdieu, Pierre (2011), A distinção: crítica social do julgamento. Porto Alegre: Zouk [2." ed.]. Tradução de Daniela Kern e Guilherme J. F. Teixeira.

Calvasina, Paola; Notions, Marilyn; Jorge, Maria; Sampaio, Helena (2007), "Fraqueza de nascença: sentidos e significados culturais de impressões maternas na saúde infantil no nordeste brasileiro", Cadernos de Saúde Pública, 23(2), 75-92.

Cano, Julieta Evangelina (2016), "La 'otredad' femenina: construcción cultural patriarcal y resistencias feministas”, Asparkía - Investigació Feminista, 29, 49-62.

Carneiro, Maria (2008), Adultos com Sindrome de Down: a deficiência mental como produção social. São Paulo: Papirus. 
Castel, Robert (2011), Desigualdade e a questão social. São Paulo: Educ.

Crooks, Valorie; Dorn, Michael; Wilton, Robert (2008), "Emerging Scholarship in the Geographies of Disability”, Health \& Place, 14, 883-888.

Cunha, Teresa (2015), "Women inPower Women" - Outras economias criadas e lideradas por mulheres no Sul não-imperial. Buenos Aires: CLACSO.

D’Ávila, Manuela (2019), Revolução Laura: reflexões sobre maternidade e resistência. Caxias do Sul: Belas Letras.

Dourado, Viviani Guilherme; Pelloso, Sandra Marisa (2007), "Gravidez de alto risco: o desejo e a programação de uma gestação”, Acta Paulista de Enfermagem, 20(1), 69-74.

Faria, Marina Dias de (2015), "A eterna criança e as barreiras do ter: consumo de pessoas com Síndrome de Down e suas famílias”. Tese de Doutorado em Administração, Instituto COPPEAD, Universidade Federal do Rio de Janeiro, Rio de Janeiro, Brasil.

Faria, Marina Dias de; Casotti, Letícia Moreira (2017), "Barreiras do ter e pessoas com Síndrome de Down: o papel do marketing na exclusão social”, Desenvolve - Revista de Gestão do Unilasalle, 6(2), 9-29.

Faria, Marina Dias de; Casotti, Leticia Moreira (2019), "Welcome to Holland People with Down Syndrome as Vulnerable Consumer”, European Jornal of Marketing, 53.

Faria, Marina Dias de; Casotti, Leticia; Carvalho, José Luis (2016), “A vulnerabilidade do consumidor com Síndrome de Down”, Anais do Encontro de Marketing da ANPAD. Belo Horizonte: ANPAD.

Fontes, Fernando (2009), "Pessoas com deficiência e políticas sociais em Portugal: da caridade à cidadania social”, Revista Crítica de Ciências Sociais, 86, 73-93. DOI: $10.4000 /$ rccs. 233

Fontes, Fernando (2016), Pessoas com deficiência em Portugal. Lisboa: Fundação Francisco Manuel dos Santos.

Fontes, Fernando; Martins, Bruno (2015), "Deficiência e inclusão social: os percursos da lesão medular em Portugal”, Sociologia, Problemas e Práticas, 77, 153-172.

Fournier, Jean-Louis (2008), Aonde a gente vai, papai? Rio de Janeiro: Intríseca. Tradução de Marcelo Jacques Moraes.

Goffman, Erving (2008), Estigma: notas sobre a manipulação da identidade deteriorada. Rio de Janeiro: LTC [4. ${ }^{a}$ ed.]. Tradução de Mathias Lambert.

Hall, Allan; Wellman, Barry (1985), "Social Networks and Social Support", in Sheldon Cohen; Leonard Syme (orgs.), Social Support and Health. San Diego: Academic Press, 23-41.

Hanisch, Halvor (2011), "Disabled Adolescence - Spaces, Places and Plans for the Future: A Case Study”, European Journal of Disability Research, 5(1), 93-103.

Karadag, Gulendan (2009), "Hardships Undergone by Mothers with Handicapped Children, Hopelessness and Social Support from Family", Preventive Medicine Bulletin, 8(4), 315-322. 
Le Breton, David (2006), A sociologia do corpo. Petrópolis: Vozes [4. a ed.]. Tradução de Sonia M. S. Fuhrmann.

Leitão, Graça (2015), "Promoção da autodeterminação em pessoas com deficiências e incapacidades: reflexões em torno de um percurso profissional”. Dissertação de Mestrado em Psicologia da Educação, Desenvolvimento e Aconselhamento, Faculdade de Psicologia da Universidade de Coimbra, Coimbra, Portugal.

Lima, Suzana; Botelho, Delane (2014), "Culpa das mães para com seus filhos e sua relação com decisões de consumo", in Anais do XXXVIII Encontro da ANPAD, 38. Rio de Janeiro: ANPAD, 1-18.

Martins, Bruno Sena (2005), "Políticas sociais na deficiência: exclusões perpetuadas", Oficina do CES, 228. Consultado a 22.01.2019, em https://ces.uc.pt/publicacoes/ oficina/ficheiros/228.pdf.

Martins, Bruno Sena; Fontes, Fernando; Hespanha, Pedro (2017), "Spinal Cord Injury in Portugal: Institutional and Personal Challenges", Journal of Disability Policy Studies, 28(2), 119-128.

Martins, Bruno Sena; Santos, Boaventura de Sousa (2018), "Socialismo, democracia e epistemologias do Sul. Entrevista com Boaventura de Sousa Santos", Revista Crítica de Ciências Sociais, número especial, 9-54. DOI: 10.4000/rccs.7647

Meneses, Verônica Dantas; Miranda, Cynthia Mara (2015), "Reflexões sobre a cultura da imagem e o imaginário feminino na publicidade”, Revista Observatório, 1(1), 171-193.

Paixão, Adriana Gomes (1997), "Representações sociais e a síndrome de Down: entre o sofrimento e a sua superação", Arquivos Brasileiros de Pediatria, 4(5), 141-146.

Pavia, Teresa; Mason, Marlys (2012), "Inclusion, Exclusion and Identity in the Consumption of Families Living with Childhood Disability", Consumptions Markets \& Culture, 15(1), 87-115.

Piccinini, Cesar; Gomes, Aline; Nardi, Tatiana; Lopes, Rita (2008), "Gestação e a constituição da maternidade”, Psicologia em Estudo, Maringá, 13(1), 63-72.

Pinto, Ana Margarida (2011), "Ser mãe de uma criança com Trissomia 21: sentimentos e expectativas”. Dissertação de Mestrado em Ciências da Educação, Faculdade de Educação, Universidade de Aveiro, Aveiro, Portugal.

Portugal, Sílvia (2007a), "Contributos para uma discussão do conceito de redes na teoria sociológica”, Oficina do CES, 271. Consultado a 11.08.2018, em https://ces.uc.pt/ publicacoes/oficina/ficheiros/271.pdf.

Portugal, Sílvia (2007b), "O que faz mover as redes sociais? Uma análise das normas e dos laços”, Revista Crítica de Ciências Sociais, 79, 35-56. DOI: 10.4000/rccs.723

Portugal, Sílvia; Nogueira, Cláudia; Hespanha, Pedro (2014), "As teias que a doença tece: a análise das redes sociais no cuidado da doença mental”, DADOS - Revista de Ciências Sociais, 57(4), 935-968.

Rocha, Ana Margarida; Leal, Isabel; Maroco, João (2007), “A amamentação, o feminino e o materno”, Análise Psicológica, Lisboa, 25(3), 363-380. 
Rodrigues, Maria (2016), "Envelhecer a cuidar de filhos com Trissomia 21: experiências de casais portugueses”. Dissertação de Mestrado em Gerontologia, Departamento de Ciências Médicas, Universidade de Aveiro, Aveiro, Portugal.

Rook, Dennis (1985), “The Ritual Dimension of Consumer Behavior”, The Journal of Consumer Research, 12(3), 251-264.

Santos, Boaventura de Sousa (2018), O fim do império cognitivo. Coimbra: Edições Almedina.

Santos, Boaventura de Sousa; Araújo, Sara; Baumgarten, Maíra (2016), “As epistemologias do Sul num mundo fora do mapa”, Sociologias, 18(43), 14-23.

Silva, Gisele da; Santos, Manoel Antônio dos (2009), "Álbum de família e esquizofrenia: convivência em retrato", Psicologia em Estudo, 14(1), 83-91.

Souza, Juliana Mello (2017), "Feminina e não feminista: a construção mediática do backlash, do consumo e dos pós-feminismos”, Media \& Jornalismo, 17(30), 71-83. Vigano, Samira de M. Maia; Laffin, Maria Hermínia L. F. (2019), "Mulheres, políticas públicas e combate à violência de gênero”, História, 38, e2019054. Consultado a 13.08.2018, em https://www.scielo.br/pdf/his/v38/1980-4369-his-38-e2019054.pdf.

Wellman, Berry; Berkowitz, Saulo (1991), Social Structures: A Network Approach. Cambridge: Cambridge University Press.

Artigo recebido a 08.05.2019

Aprovado para publicação a 07.05.2020

\section{Marina Dias de Faria}

Centro de Ciências Jurídicas e Políticas, Universidade Federal do Estado do Rio de Janeiro

Rua Voluntários da Pátria, 107, CEP: 22270-000 Botafogo, Rio de Janeiro, Brasil

Contacto: marina.faria@unirio.br

ORCID: https://orcid.org/0000-0001-6334-145X

\section{How Down Syndrome Does Not Weave Webs: Identity, Stigma and Social Exclusion}

The objective of the present research is to use the network theory to analyze the configuration of the social webs of adults with Down Syndrome (DS). The main potential of social network analysis is to point out that the individual is conditioned

\section{Les réseaux faibles du syndrome de Down: identité, stigmatisation et exclusion sociale}

La présente recherche visait à utiliser la théorie des réseaux pour analyser la configuration des réseaux sociaux d'adultes atteints du syndrome de Down (SD). Cette théorie a comme principale potentialité de souligner que l'individu est conditionné 
by the social network that surrounds him and is also able to modify this network. Interviews were conducted with 34 families in Portugal and Brazil. Respondents were adults with DS and their mothers. The results showed that the network of the DS individuals is narrow and has as main node the maternal figure. The mother is responsible in almost all the families interviewed for taking care of her child with DS, even if she has to give up her moments of leisure and her profession. The network of people with DS is mainly composed of women, and people outside of the family often create negative bonds with these individuals.

Keywords: disability; Down Syndrome; mothers; network theory; social exclusion. par le tissu social qui l'entoure et qu'il est également capable de modifier ce tissu. Des entretiens ont été menés auprès de 34 familles au Brésil et au Portugal. Les personnes interrogées étaient des adultes atteints de SD et leurs mères. Les résultats ont montré que le réseau d'individus atteint de SD est faible et a comme nœud principal la figure maternelle. Les mères sont responsables dans presque toutes les familles interviewées de s'occuper des enfants avec SD, même si elles doivent renoncer à leur temps libre et à leurs professions. Il est clair que le réseau de personnes atteintes du SD est composé principalement de femmes et que les personnes en dehors de la famille créent souvent des liens négatifs avec ces personnes. Mots-clés: déficience; exclusion sociale; mères; syndrome de Down; théorie des réseaux. 
